\title{
Absorption of electrolytes and volatile fatty acids in the hind-gut of the rabbit. Circadian rhythm of hind-gut electrolytes and plasma aldosterone
}

\author{
BY MICHELE VERNAY \\ Institut de physiologie, 2 rue F. Magendie, 31400-Toulouse, France
}

AND JOSETTE MARTY

Laboratoire de Biologie générale ERA-CNRS, 327 Université Paul Sabatier, 118 route de Narbonne, 31062 Toulouse-Cédex, France

AND JEAN-PIERRE MOATTI

Biochimie III-Hôpital de la Grave, 31062 Toulouse-Cédex, France

(Received 9 November 1983 - Accepted 30 April 1984)

\begin{abstract}
1. Interrelationships between the amount of water, solute concentrations in the hind-gut, plasma aldosterone concentrations, and the excretory cycle in the rabbit were studied as well as the effects of hormones generally implicated in electrolyte regulation.

2. It appeared that the levels of water, electrolytes and volatile fatty acids (VFA) in the large intestine varied cyclicly with the excretion pattern: during the soft-phase, water, sodium, chloride and VFA were absorbed and potassium secreted as in other mammals; during the hard-phase two opposite phenomena occurred: secretion in the ascendant colon and absorption in the rest of the colon. Absorption of water, $\mathrm{Na}, \mathrm{K}$, chloride and VFA was increased and by this means only material without nutritional value was lost.

3. Plasma levels of aldosterone showed a circadian rhythm parallel to hind-gut changes, i.e. the higher values were found during the hard-phase. Exogenous aldosterone enhanced secretive and absorptive processes, which occurred normally when hard faeces were elaborated.
\end{abstract}

The mammalian large intestine is important for the maintenance of water and electrolyte balance. It absorbs water, sodium, chloride and volatile fatty acids (VFA) and secretes potassium and bicarbonate. $\mathrm{Na}$, the main cation entering the colon, is absorbed by active transport. This active process is the primary activity driving the movement of fluid and other electrolytes through the paracellular pathway. The negative mucosal potential difference (PD) should favour chloride absorption and $\mathrm{K}$ secretion. Although there is general agreement that active $\mathrm{Na}$ transport is present, considerable controversy exists about the overall mechanism of $\mathrm{K}$, chloride and bicarbonate transport in the large intestine (Edmonds, 1967, 1969; Turnberg et al. 1970a, b; Giller et al. 1972; Binder \& Rawlins, 1973; Frizzell et al. 1976; Schultz, 1977; Yorio \& Bentley, 1977). For the rabbit the situation is complicated by the occurrence of an excretion pattern of two types of faeces generally described as hard faeces and soft faeces. To understand the discrepancies found in the literature we thought it necessary to examine the changes in the amounts of water, electrolytes and VFA along the hind-gut. The present study was designed to study (a) the relationships between water, electrolytes and VFA levels in the large intestine, plasma values of aldosterone and the excretion pattern of the rabbit, and (b) the effects of exogenous antidiuretic hormone (ADH) and aldosterone on water and solute transport in colonic loops of anaesthetized animals. 
MATERIALS AND METHODS

\section{Animals}

A total of thirty-eight male rabbits (Oryctolagus cuniculus) weighing about $2.5 \mathrm{~kg}$ were used. Animals were given oats, lucerne (Medicago sativa) and water ad lib. The experiments were carried out either between $\mathbf{0 4 . 0 0}$ and $\mathbf{0 7 . 0 0}$ hours (period of soft-faeces formation) or between 10.00 and 18.00 hours (period of hard-faeces formation). Therefore groups were selected on the basis of their excretion pattern: soft-phase when faeces elaborated in the colon were soft, hard-phase when faeces elaborated were hard.

\section{Experimental procedure}

Two types of experiments were performed. In the first, twenty-eight animals were divided into two equal groups: one group elaborated soft faeces, the other group elaborated hard faeces. On conscious rabbits, blood was obtained by puncturing the marginal ear artery and was collected into heparinized tubes. The animals were then killed and the large intestine was immediately removed and separated by ligatures into segments. The caecum was taken as one single segment but the colon was divided into five segments: ascendant (segments $1-2$ ), transverse (segment 3) portions of the proximal colon and distal colon (segments 4-5). In the second experiment, ten rabbits were anaesthetized by administration of a nembutal solution $(20 \mathrm{mg} / \mathrm{kg})$ via the marginal ear vein. For the study of the effects of $\mathrm{ADH}$ and aldosterone on water and solute transport in the intestine, colonic loops were prepared after laparotomy from ascendant and transverse or descendant segments. Their contents were carefully washed out with physiological saline $(9 \mathrm{~g}$ sodium chloride $/ 1)$ at $38^{\circ}$. The loops were filled with $5 \mathrm{ml}$ of the test solution (Leng \& Hörnicke, 1975) containing $2 \mathrm{~g}$ polyethylene glycol (PEG)/l and $20 \mu \mathrm{Ci}\left[1,2-{ }^{14} \mathrm{C}\right] \mathrm{PEG}$ (molecular.weight 4000 ; New England Nuclear)/1. At the end of the incubation period $(60 \mathrm{~min})$ loops were emptied and removed. Control studies have shown that exogenous aldosterone was predominantly effective during the hard-phase, thus experiments were performed when animals elaborated hard faeces. ADH (Postacton, Ferring) was injected via the marginal ear vein $(2.5 \mathrm{IU} / \mathrm{kg})$ and aldosterone (Serva, Feinbiochemica) was administered intramuscularly $(30 \mu \mathrm{g} / \mathrm{kg})$.

\section{Preparation of samples}

The material of each segment was weighed, homogenized and the water content of the intestinal matter determined by drying a portion at $110^{\circ}$ for $24 \mathrm{~h}$; the $\mathrm{pH}$ was immediately measured with a pH meter (Metrohm E 532), the wet material extracted with distilled water and the suspension centrifuged for $20 \mathrm{~min}$ at $10000 \mathrm{~g}$. The supernatant fraction was filtered and concentrations of electrolytes and VFA were measured in the fluid obtained. Heparinized blood and the test solutions of colonic loops were quickly centrifuged under liquid paraffin (Eppendorf-Zentrifuge 3200)for $2 \mathrm{~min}$. Bicarbonates were measured automatically (Corning, Model 960 ) ${ }^{14} \mathrm{C}$ activity was assayed in $100-\mu \mathrm{l}$ of sample added to $10 \mathrm{ml}$ Instagel (Packard Instruments) using a liquid-scintillation counter (Packard $460 \mathrm{C}$ ); $\mathrm{Na}$ and $\mathrm{K}$ were detected by flame photometry (Gallenkamp) and chloride by a colorimetric micromethod (Beckman). The VFA of the material and blood were determined after extraction as described by Rémésy (1973) and Rémésy \& Demigné (1974), while VFA of the test colonic solutions were measured after acidification of $1 \mathrm{ml}$ of the sample with $100 \mu \mathrm{l}$ formic acid; VFA were analysed by gas-liquid chromatography (Intersmat IGC 120 DSI). The plasma concentration of aldosterone was determined by a radioimmunoassay technique based on that of Bayard et al. (1970). 


\section{Calculations}

For the hind-gut contents results are expressed as $\mathrm{mm}$ and in relation to the concentrations found in the caecum, which were taken as a reference $(100 \%)$. In colonic loops, the variations of the net fluxes are expressed as a percentage of the initial concentration. All the results are presented as means with their standard errors. Differences were evaluated statistically using paired or unpaired Student's $t$ test, as appropriate.

\section{RESULTS}

\section{Diurnal variations in the hind-gut contents}

Changes in the excretion pattern produced only small modifications in caecal contents (Table 1); during the hard-phase it appeared that $\mathrm{K}$ values were significantly higher than those during the soft-phase $(P<0.01)$. In contrast, during colonic transit, important changes occurred in the composition of the digesta. These changes were linked with the excretion pattern and location in the gut (Fig. 1).

At the time of elaboration of soft faeces, water, Na, chloride and VFA values decreased significantly from caecum to transverse colon $(P<0.001)$; meanwhile $\mathrm{K}$ concentration rose markedly $(P<0.001)$. Conversely, the mean Na: K value dropped from $2.6(\mathrm{SE} 0.24)$ to 1.0 (SE 0.24). During transit in the descendant colon there was very little further modification except for $\mathrm{K}$ which still increased $(P<0.001)$. Faecal $\mathrm{Na}: \mathrm{K}$ was slightly reduced 0.9 (sE 0.21 ). Mean values of $\mathrm{pH}$ along the hind-gut became slightly acidic, changing from 6.5 (SE $0 \cdot 14)$ to $6 \cdot 1$ (SE $0 \cdot 18$ ).

When hard faeces were elaborated, characteristic profiles were found: water, $\mathrm{K}$ and chloride contents of digesta increased in the ascendant colon $(P<0.001)$, the $\mathrm{Na}$ level was practically constant and only VFA concentrations diminished. All indices measured decreased sharply during passage through the transverse and descendant colon. Faecal $\mathrm{Na}: \mathrm{K}$ fell to $0 \cdot 3$ (SE 0.09). The pH values increased along the hind-gut from 6.5 (SE 0.23) to $7 \cdot 7$ (SE $0 \cdot 10$ ). In the descendant colon the composition of hard faeces differed significantly from that of soft faeces $(P<0.001)$.

Table 1. Concentrations ( $m M$ ) of electrolytes and volatile fatty acids $(V F A), p H$ values and water weight $(\%)$ in the caecal contents of rabbits in relation to excretion pattern

(Mean values with their standard errors; no. of observations in parentheses)

\begin{tabular}{|c|c|c|c|c|}
\hline & \multicolumn{2}{|c|}{ Soft-phase (14) } & \multicolumn{2}{|c|}{ Hard-phase (14) } \\
\hline & Mean & $\mathbf{S E}$ & Mean & SE \\
\hline Water & $82 \cdot 0$ & 0.94 & $79 \cdot 1^{*}$ & 0.75 \\
\hline Sodium & $78 \cdot 1$ & $6 \cdot 80$ & $89 \cdot 0$ & $9 \cdot 00$ \\
\hline Potassium & $33 \cdot 6$ & 2.79 & $42 \cdot 4 * *$ & $3 \cdot 12$ \\
\hline Chloride & $22 \cdot 1$ & 1.83 & $21 \cdot 7$ & $3 \cdot 21$ \\
\hline Bicarbonate & $14 \cdot 5$ & $7 \cdot 76$ & $16 \cdot 8$ & 6.91 \\
\hline VFA & $70 \cdot 6$ & 5.94 & $76 \cdot 6$ & $9 \cdot 59$ \\
\hline $\mathrm{pH}$ & $6 \cdot 5$ & $0 \cdot 14$ & $6 \cdot 5$ & $0 \cdot 14$ \\
\hline $\mathrm{Na}: \mathrm{K}$ & $2 \cdot 6$ & 0.35 & $2 \cdot 2$ & $0 \cdot 21$ \\
\hline
\end{tabular}

Mean values for caecal components in relation to excretion pattern were significantly different: ${ }^{*} P<0 \cdot 05$, ** $P<0.01$. 

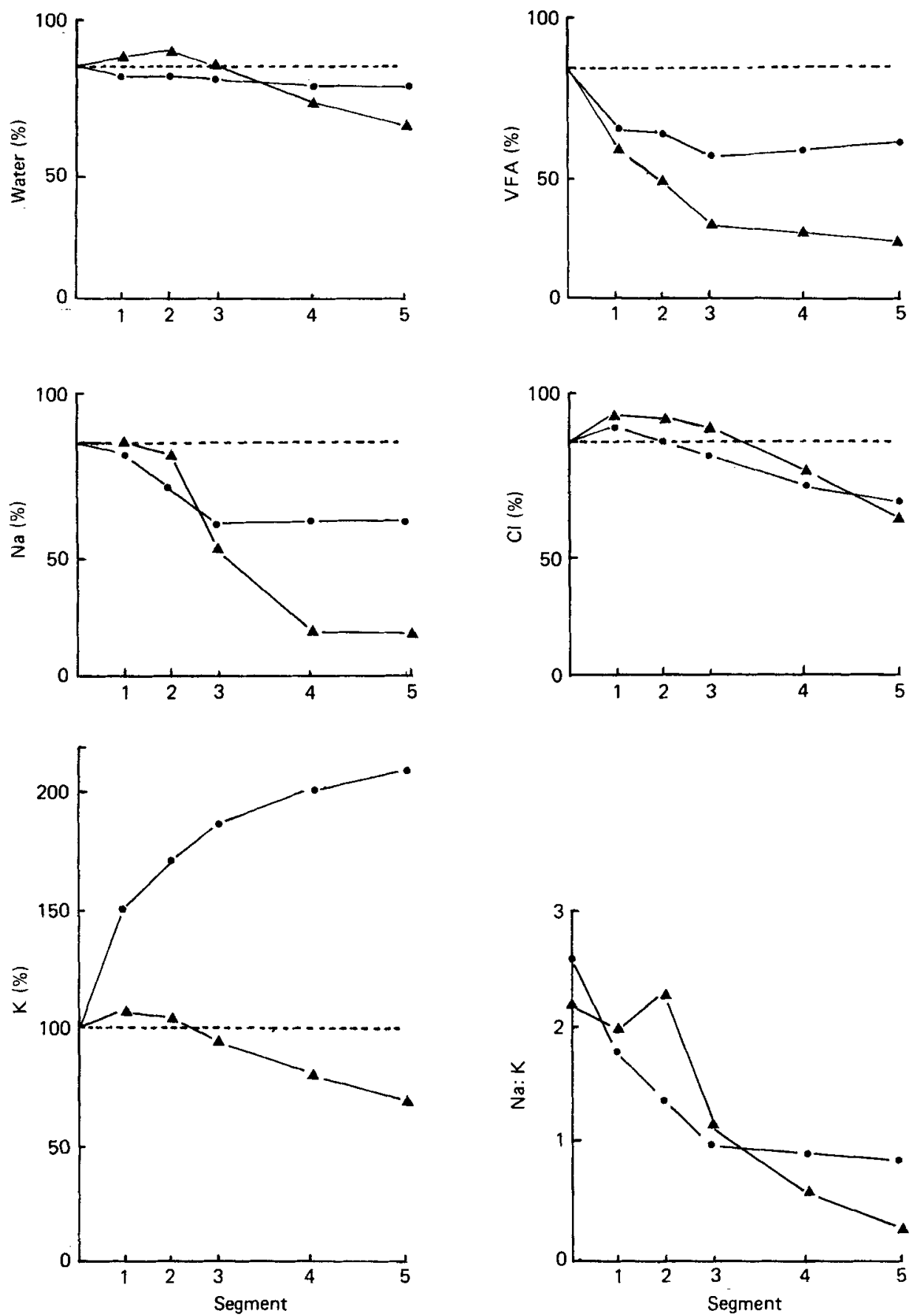

Fig. 1. Variations of water, electrolytes, volatile fatty acids (VFA) and $\mathrm{Na}: \mathrm{K}$ in the hind-gut contents. Points are mean values for fourteen samples during the soft-phase and fourteen samples during the hard-phase. Values are expressed as a percentage of the concentration in the caecum. (O), Soft-phase; (A) hard-phase; segments 1-2, ascendant colon; segment 3, transverse colon; segments 4-5, descendant colon. The standard errors $(\%)$ in the different regions were: water $0 \cdot 9-1 \cdot 7$, sodium $6 \cdot 8-11 \cdot 0$, potassium $2 \cdot 6-11 \cdot 6$, chloride 1.4-2.9, VFA, 1.9-6.6; Na:K, $0 \cdot 1-0 \cdot 2$. 

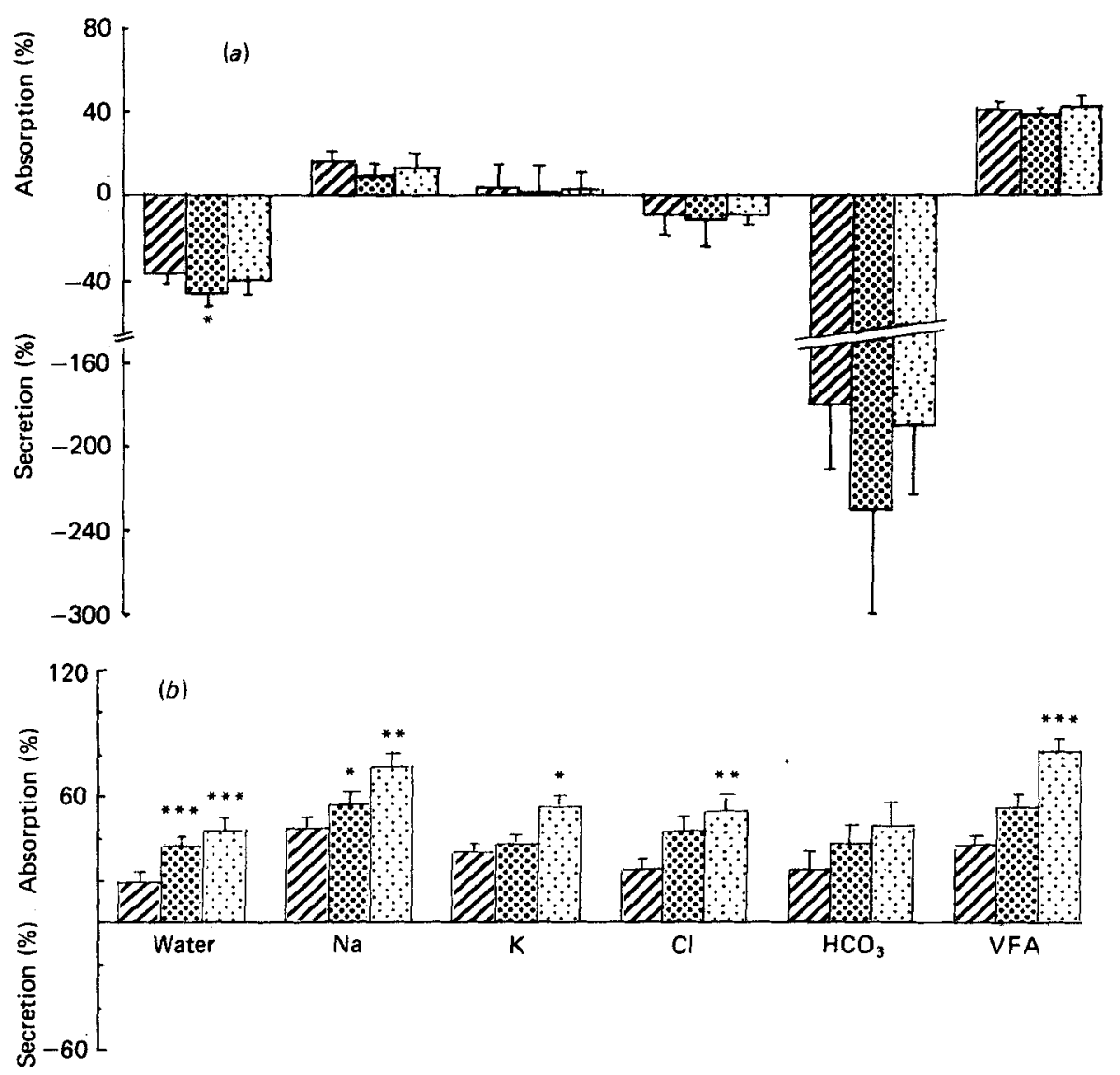

Fig. 2. Influence of antidiuretic hormone (ADH) and aldosterone on the net fluxes of water, electrolytes and volatile fatty acids (VFA) in (a) ascendant colonic loops and $(b)$ in transverse and descendant colonic loops. Points are mean values with their standard errors represented by vertical bars for twenty observations in control experiments, ten observations in ADH experiments and ten observations in aldosterone experiments. Values are expressed as a percentage of the concentration of the test solution at the start of the experiment. (促), Control; ( $\mathrm{W}$ ), ADH; (圈), aldosterone. Mean values for control and $\mathrm{ADH}$ or aldosterone experiments were significantly different: ${ }^{*} P<0.05,{ }^{* *} P<0.01$, *** $P<0.001$.

\section{Hormonal effects on the net fux of water and solutes in colonic loops}

Examination of Fig. 2 shows that during the hard-phase in the ascendant segment, there was a net secretion of water and bicarbonate $(P<0.001)$ and a net absorption of VFA $(P<0 \cdot 001)$; meanwhile net fluxes of $\mathrm{Na}, \mathrm{K}$ and chloride had no definite direction (Fig. $2 a$ ). However, in transverse and descendant segments all measured indices decreased significantly showing an important absorption of the corresponding substances (Fig. $2 b$ ). Exogenous ADH and aldosterone affected the colonic segments differently: in the ascendant segment after administration of ADH or aldosterone, net water secretion was enhanced $(P<0.05)$, net $\mathrm{Na}$ absorption was slightly but not significantly reduced and the net transport of K, chloride, bicarbonate and VFA appeared to show no difference from that seen in control experiments (Fig. $2 a$ ). In the rest of the colon, ADH augmented water absorption $(P<0.001)$ but the net flux for the other indices remained relatively constant. In contrast, the disappearance of water, $\mathrm{Na}, \mathrm{K}$, chloride and VFA was consistently higher after administration of aldosterone (Fig. $2 b$ ). 
Table 2. Concentrations ( $m M$ ) of electrolytes, volatile fatty acids $(V F A)$ and aldosterone (ng/l), $\mathrm{pH}$ values in arterial plasma of rabbits in relation to excretion pattern

(Mean values with their standard errors; no. of observations in parentheses)

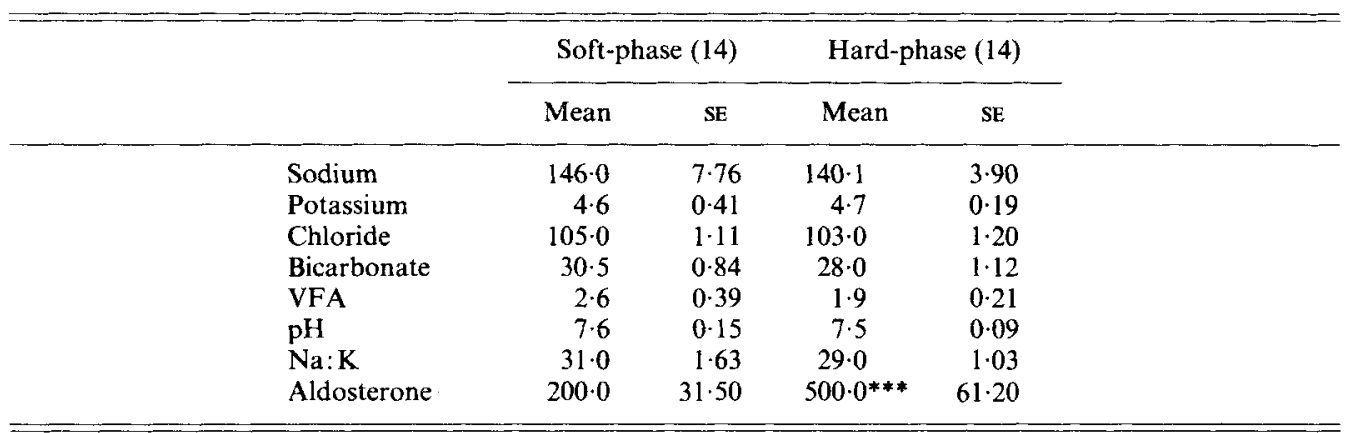

Mean values for plasma aldosterone in relation to excretion pattern were significantly different: *** $P<0.001$.

\section{Diurnal plasma variations}

Mean values for plasma aldosterone showed variations in relation to the excretion pattern, concentrations were two times higher during the hard-phase than during the soft-phase $(P<0.001)$. It appeared that there were no detectable variations in $\mathrm{pH}$ values, levels of electrolytes and VFA in arterial plasma (Table 2).

\section{DISCUSSION}

Water, electrolytes and VFA obtained from the gut contents exhibit an irregular concentration gradient along the large intestine. There is a decline in the level of VFA during passage of digesta through the entire colon (Henning \& Hird, 1972; Vernay \& Raynaud, 1975; Bonnafous \& Raynaud, 1978), however, because of the close relationship between VFA and $\mathrm{Na}$ and $\mathrm{K}$ transport in the colon (M. Vernay and J. Marty, unpublished results), regional irregularities in the VFA profile were found. It is interesting to note that water and electrolytes varied markedly with the excretion pattern as well as the site from which samples were obtained.

During the elaboration of soft faeces, the rabbit colon conserves water, $\mathrm{Na}$ and chloride and secretes $\mathrm{K}$ as in the large intestine of man (Devroede \& Phillips, 1969; Hawker et al. 1978; McNeil \& Cummings, 1979), rat (Edmonds, 1967, 1969; Edmonds \& Marriott, 1967; Edmonds \& Thompson, 1980), dog (Phillips \& Code, 1966) and turtle (Halm \& Dawson, 1980).

$\mathrm{K}$ concentration in the faecal fluid is relatively high, usually exceeding $60 \mathrm{~mm}$. Although the PD favours development of an intraluminal $\mathrm{K}$ concentration several times that of the blood, it cannot be more than a minor factor in the intact animal, since in our study $\mathrm{K}$ level was greater than that predicted by the Nernst equation. In effect, in rabbit, the average normal PD is about $40 \mathrm{mV}$ (Yorio \& Bentley, 1977; Snipes et al. 1982), which can support an intraluminal $\mathrm{K}$ of only $20 \mathrm{~mm}$. The fact that conditions are not at equilibrium is obviously important and the nature of the $\mathrm{K}$ secretory process is a matter of debate. In a series of radioisotopic studies of the isolated rabbit descendant colon epithelium, Frizzell et al. (1976), Frizzell \& Schultz (1978) and Fromm \& Schultz (1981) observed no net transport of $\mathrm{K}$ under in vitro short-circuited conditions and they concluded that $\mathrm{K}$ transport occurred by diffusion through a highly $\mathrm{K}$-selective paracellular pathway. Other investigators, however, argue against a purely diffusional mechanism for $\mathrm{K}$ transport and Wills et al. 
(1979), McCabe et al. (1982) and Wills \& Biagi (1982) demonstrated that, in addition to paracellular movement, $\mathbf{K}$ can also be transported by transcellular mechanisms. An uphill movement of $\mathrm{K}$ is also found in the colon of man (Salas-Coll et al. 1976; Hawker et al. 1978; McNeil \& Cummings, 1979) and rat (Edmonds, 1967, 1969; Edmonds \& Marriott, 1967; Edmonds \& Thompson, 1980).

During the excretion of hard faeces, the electrolyte composition of the intestinal contents undergoes initial marked changes in the proximal colon where an important phenomenon occurs. The ascendant segment of the rabbit colon, in vivo, has been shown to secrete water and bicarbonate effectively from a saline solution corresponding to normal electrolyte caecal fluid. This colonic secretion is of great importance for the orientation of digesta towards hard faeces, it contains a lytic protein characterized by Bonnafous \& Raynaud (1968a, 1969, 1973) which is responsible for the steady fall in the bacterial population of the transverse and descendant colon (Bonnafous \& Raynaud, 1970). Colonic secretion also permits dilution of the material and separation of two phases: a liquid phase with small particles and a solid phase, the former being refluxed into the caecum, the latter being voided with hard faeces (Björnhag, 1972, 1981; Ruckebusch \& Hörnicke, 1977). By contrast, in other parts of the large intestine absorptive phenomena occur and they are responsible for the striking decrease in water, $\mathrm{Na}, \mathrm{K}$ and chloride during the passage of material through the length of the colon. Paradoxically, when hard faeces are elaborated $\mathrm{K}$ concentration falls. This disappearance against an electrical gradient suggests that net $\mathrm{K}$ absorption requires an active uptake at the apical border with a diffusional exit step across the basolateral membrane. It is unlikely that this system is an ouabain-sensitive $\left(\mathrm{Na}^{+}-\mathrm{K}^{+}\right)$ATPase situated in the apical membrane, as suggested by the results of Husted \& Steinmetz (1980) for K absorption in the turtle bladder, since luminally applied ouabain had virtually no effect on the net K absorption (Gustin \& Goodman, 1982; Wills \& Biagi, 1982). It appears that this absorptive system is coupled to the transport of other ions such as chloride, hydrogen and VFA (M. Vernay and J. Marty, unpublished results). Our findings are consistent with the work of Gustin \& Goodman $(1981,1982)$. These workers showed that the rabbit colon brush-border membrane possesses a unique $\mathrm{K}^{+}$-stimulated, ouabain-insensitive ATPase, this enzyme being similar to the gastric $\left(\mathrm{H}^{+}-\mathrm{K}^{+}\right)$ATPase. It seems that $\mathrm{K}$ transport in the rabbit is mediated, at least in part, by two active-transport systems: a secretory and an absorptive one. It is possible that both these systems may work together to regulate intracellular K activity levels. The possibility of the existence of both mechanisms which are controlled by the metabolic state of the rabbit may explain some of the discrepancies found in the literature. Absorptive and secretory processes are also reported for in vitro colonic preparations of turtle (Halm \& Dawson, 1980) and rat (Kliger et al. 1981) and in the colon of man in vivo (Giller et al. 1972).

A variety of hormones, 'local' hormones and neurohormones have been shown to influence the absorptive and secretory mechanisms of the large intestine. For the most part their significance remains obscure but for ADH and adrenal hormones there is considerable knowledge. After injection of ADH to well-hydrated rabbit tissue, there is no change in the direction of the net water and solute transport in the proximal colon, although ADH both increases the rate of fluid secretion in the ascendant segment and the rate of fluid absorption in the other segments. Such opposite action is probably mediated through a common final intracellular path, both the adenylate cyclase system (cAMP) and intracellular calcium may be involved as in other epithelia (Jard et al. 1975; Jard \& Bockaert, 1975; Rasmussen \& Goodman, 1977; Strewler \& Orloff, 1977; Kretsinger, 1979; De Souza \& Grosso, 1981). It has been demonstrated that cAMP increases water and $\mathrm{Na}$ absorption in absorptive epithelia such as toad urinary bladder, frog skin and renal tubule (Bourguet et al. 1976; Harmanci et al. 1978; Brown et al. 1979, 1980). By contrast, cAMP increases 
water and $\mathrm{Na}$ secretion in secretory epithelia of stomach, salivary glands and pancreas (Harris \& Alonso, 1965; Berridge \& Patel, 1968; Harris et al. 1969; Case et al. 1969). The actions of CAMP in the intestine display a number of differences, some related to the species, others to the segment studied or to the experimental conditions imposed. Thus cAMP inhibits the net flux of $\mathrm{Na}$ in both parts of the rat colon (Yau \& Makhlouf, 1974). However, Hornych et al. (1973) reported that cAMP stimulated Na absorption in the ascendant colon of the rat and inhibited it in the descendant colon. Addition of cAMP to the isolated ileal mucosa of man (Levitan \& Mauer, 1968; Soergel et al. 1968; Donowitz \& Binder, 1976), rat and guinea-pig (Kimberg et al. 1971) and rabbit (Field et al. 1969; Field, 1971; Frizzell et al. 1976) is followed by an increase in the short-circuit current and it is suggested that this messenger stimulates active secretion of chloride and provides a driving force for fluid secretion. We can suppose that these findings can be extended to the rabbit ascendant colon which can be considered as a mixed epithelia: absorptive during the soft-phase and secretory during the hard-phase; meanwhile the rest of the colon can be considered as an absorptive epithelia. Some doubt remains as to whether the glucocorticoids affect the colon (Duthie et al. 1964); however, Charney et al. (1975) and Binder (1976) showed that these hormones were able to provoke an increase in water and $\mathrm{Na}$ absorption in the rat. Bonnafous \& Raynaud (1968b) and Kawakami et al. (1972) reported that there was a relationship between the plasma level of glucocorticoids and the excretion pattern: plasma values were higher when hard faeces were elaborated. However, it is well established that aldosterone plays an important role in the movements of the electrolytes, it reduces $\mathrm{Na}$ and increases $\mathrm{K}$ concentration in the faeces, stimulating $\mathrm{Na}$ absorption and $\mathrm{K}$ secretion by the epithelia (Levin, 1974). Furthermore, Charney et al. (1975) showed in the intestine of the rat that when electrolyte and water transport was induced by mineralocorticoid treatment, $\left(\mathrm{Na}^{+}-\right.$ $\mathrm{K}^{+}$)ATPase activity was significantly increased. Our results demonstrate a striking association between colonic electrolyte transport and plasma aldosterone levels, in effect the higher values of plasma aldosterone were recovered during the hard-phase when water, electrolytes and VFA transfers were increased. The enhancement of $\mathrm{Na}$ absorption was certainly responsible for the greater rectal PD found at the same time by Clauss \& Hörnicke $(1979 a)$. Indeed, the stimulatory effect of aldosterone is also found when this hormone is administered to rabbits; as with ADH it involves an increase in both secretory and absorptive fluid processes but, in contrast to $\mathrm{ADH}$, the increasing absorption involves all the components studied, i.e. Na, K, chloride and VFA. In vitro experiments confirm that aldosterone elicits water and $\mathrm{Na}$ absorption on descendant colonic epithelium (Frizzell \& Schultz, 1978) but there is a contradiction for K transport, since Schultz (1981) found that aldosterone increases $\mathbf{K}$ secretion. The fact that aldosterone acts differently in the various parts of the colon is also observed in vivo in the large intestine of the rat (Edmonds \& Marriott, 1967) and in vitro in colonic preparations of the rabbit (Clauss \& Hörnicke, 1979b) and guinea-pig (Wirthensohn, 1980).

Water, electrolytes and VFA in the digesta, absorptive capacity and sensitivity of transport processes to ADH and aldosterone all exhibit a discontinuous profile reflecting the diversity of structure and permeability along the rabbit hind-gut found by Snipes $e t$ al. (1982). Aldosterone plays an important role in colonic transfer of water, electrolytes and VFA; exogenous aldosterone increases variations which occur normally when hard faeces are elaborated.

The authors wish to thank Professor Ruckebusch and $\mathrm{Mr}$ Bueno (Ecole vétérinaire) and Mr Guerre (Laboratoire privé d'analyses médicales) for allowing them to work in their laboratory. The authors are very grateful to $\mathrm{Mr}$ Abravanel (Centre de physiologie végétale) for his critical reading of the manuscript. 


\section{REFERENCES}

Bayard, F., Beitins, I. Z., Kowarsky, A. \& Migcon, C. J. (1970). Journal of Clinical Endocrinology and Metabolism 31, 1-6.

Berridge, M. J. \& Patel, N. G. (1968). Science 162, 462-463.

Binder, H. J. (1976). Gastroenterology 10, 864 (Abstr.).

Binder, H. J. \& Rawlins, C. L. (1973). American Journal of Physiology 225, 1232-1239.

Björnhag, G. (1972). Swedish Journal Agricultural Research 2, 125-136.

Björnhag, G. (1981). Swedish Journal Agricultural Research 11, 63-69.

Bonnafous, R. \& Raynaud, P. (1968a). Archives des Sciences Physiologiques 22, 57-64.

Bonnafous, R. \& Raynoud, P. (1968b). Annales d Endocrinologie 29, 331-336.

Bonnafous, R. \& Raynaud, P. (1969). Comptes Rendus Hebdomadaires des Séances de l'Académie des Sciences 269, 1004-1006.

Bonnafous, R. \& Raynaud, P. (1970). Experientia 26, 52-53.

Bonnafous, R. \& Raynaud, P. (1973). Forum de Recherches de la Société Française de Gastroentèrologie, Strasbourg, 8/9 December.

Bonnafous, R. \& Raynaud, P. (1978). 2e Journée de la Recherche Cunicole en France, communication no. 5.

Bourguet, J., Chevalier, J. \& Hugon, J. S. (1976). Biophysical Journal 16, 627-639.

Brown, D., Grosso, A. \& De Souza, R. C. (1979). Journal of Cell Biology 82, 284a.

Brown, D., Grosso, A. \& De Souza, R. C. (1980). Biochimica et Biophysica Acta 596, $158-164$.

Case, R. M., Laundy, T. J. \& Scratchard, T. (1969). Journal of Physiology 204, 45-46.

Charney, A. N., Kinsey, M. D., Myers, L. \& Giannella, R. A. (1975). Journal of Clinical Investigation 56, 653-660. Clauss, W. \& Hörnicke, H. (1979a). Chronobiologia 2, 88 (Abstr.).

Clauss, W. \& Hörnicke, H. (1979b). Gastroenterologia, Clinical Biology 3, 179 (Abstr.).

De Souza, R. C. \& Grosso, A. (1981). Journal de Physiologie 77, 643-669.

Devroede, G. J. \& Phillips, S. F. (1969). Gastroenterology 56, 101-109.

Donowitz, M. \& Binder, H. J. (1976). Journal of Infectious Diseases 134, 135-143.

Duthie, H. L., Watts, J. M., de Dombal, F. T. \& Goligher, J. C. (1964). Gastroenterology 47, 525-530.

Edmonds, C. J. (1967). Journal of Physiology 193, 589-602.

Edmonds, C. J. (1969). Journal of Physiology 203, 533-554.

Edmonds, C. J. \& Marriott, J. C. (1967). Journal of Endocrinology 39, 517-531.

Edmonds, C. J. \& Thompson, B. D. (1980). Journal of Physiology 302, 399-409.

Field, M. (1971). American Journal of Physiology 221, 992-997.

Field, M., Fromm, D., Wallace, C. \& Greenough, W. B. (1969). Journal of Clinical Investigation 48, 24a.

Frizzell, R. A., Koch, M. J. \& Schultz, S. G. (1976). Journal of Membrane Biology 27, 297-316.

Frizzell, R. A. \& Schultz, S. G. (1978). Journal of Membrane Biology 39, 1-26.

Fromm, M. \& Schultz, S. G. (1981). Journal of Membrane Biology 63, 93-98.

Giller, J., Phillips, S. F. \& Phillips, M. D. (1972). American Journal of Digestive Diseases 17, 1003-1011.

Gustin, M. C. \& Goodman, D. B. P. (1981). Journal of Biological Chemistry 256, 10651-10656.

Gustin, M. C. \& Goodman, D. B. P. (1982). Journal of Biological Chemistry 257, 9629-9633.

Halm, D. R. \& Dawson, D. C. (1980). Federation Proceedings 39, 738 (Abstr.).

Harmanci, M. C., Kachadorian, W. A., Valtin, H. \& Discala, V. A. (1978). American Journal of Physiology 235, F440-F443.

Harris, J. B. \& Alonso, D. (1965). Federation Proceedings 24, 1368-1376.

Harris, J. B., Nigon, K. \& Alonso, D. (1969). Gastroenterology 57, 377-384.

Hawker, P. C., Mashiter, K. E. \& Turnberg, L. A. (1978). Gastroenterology 74, 1241-1247.

Henning, S. J. \& Hird, F. J. R. (1972). British Journal of Nutrition 27, 57-64.

Hornych, A., Meyer, P. \& Millicz, P. (1973). American Journal of Physiology 224, 1223-1227.

Husted, R. F. \& Steinmetz, P. R. (1980). Journal of General Physiology 76, $28 \mathrm{a}$.

Jard, S. \& Bockaert, J. (1975). Physiological Reviews 55, 489-536.

Jard, S., Roy, C., Barth, T., Rajerison, R.\& Bockaert, J. (1975). Advances in Cyclic Nucleotides Research 5, 31-52.

Kawakami, M., Seto, K. \& Kimura, F. (1972). Neuroendocrinology 9, 207-214.

Kimberg, D. V., Field, M., Johnson, J., Henderson, A. \& Gershon, E. (1971). Journal of Clinical Investigation 50, $1218-1230$.

Kliger, A. S., Binder, H. J., Bastl, C., Hayslett, J. P. \& Flein-Robbenhaar, T. (1981). Journal of Clinical Investigation 67, 1189-1196.

Kretsinger, R. H. (1979). Advances in Cyclic Nucleotides Research 11, 1-26.

Leng, E. \& Hörnicke, H. (1975). Zeitschrift für Versuchtierkunde 17, 285-299.

Levin, R. J. (1974). In General Comparative and Clinical Endocrinology of the Adrenal Cortex, vol. 1, 207-291

[I. Chester-Jones and I. W. Henderson, editors]. London: Academic Press.

Levitan, R. \& Mauer, I. (1968). Journal of Laboratory and Clinical Medicine 72, 739-746.

McCabe, R., Cooke, H. J. \& Sullivan, L. P. (1982). American Journal of Physiology 242, C81-C86.

McNeil, N. I. \& Cummings, J. H. (1979). Gut 20, A439 (Abstr.).

Phillips, S. F. \& Code, C. F. (1966). American Journal of Physiology 211, 607-613. 
Rasmussen, H. \& Goodman, D. B. P. (1977). Physiological Review 57, 421-509.

Rémésy, C. (1973). Contribution à l'étude de la production et du métabolisme des acides gras volatils chez le rat. Thèse de spécialité, Université de Clermont-Ferrand.

Rémésy, C. \& Demigné, C. (1974). Biochemical Journal 141, 85-91.

Ruckebusch, Y. \& Hörnicke, H. (1977). Physiology and Behaviour 18, 871-878.

Salas-Coll, C. A., Kermode, J. C. \& Edmonds, C. J. (1976). Clinical Science and Molecular Medicine 51, $287-296$.

Schultz, S. G. (1977). American Journal of Physiology 2, E249-E254.

Schultz, S. G. (1981). Federation Proceedings 40, 2408-2411.

Schultz, S. G., Frizzell, R. A. \& Nellans, H. N. (1977). Journal of Membrane Biology 33, 351-384.

Snipes, R. L., Clauss, W., Weber, A. \& Hörnicke, H. (1982). Cell and Tissue Research 225, 331-346.

Soergel, K. H., Whalen, G. E. \& Harris, J. A. (1968). Journal of Clinical Investigation 47, 1071-1082.

Strewler, G. J. \& Orloff, J. (1977). Advances in Cyclic Nucleotides Research 8, 311-361.

Turnberg, L. A., Biederdorf, F. A., Morawski, S. G. \& Fordtran, J. S. (1970 b). Journal of Clinical Investigation 49, 557-567.

Turnberg, L. A., Fordtran, J. S., Carter, N. W. \& Rector, F. C. (1970a). Journal of Clinical Investigation 49, $548-556$.

Vernay, M. \& Raynaud, P. (1975). Annales de Recherches Vétérinaires 6, 357-377.

Wills, N. K. \& Biagi, B. (1982). Journal of Membrane Biology 64, 195-203.

Wills, N. K., Lewis, S. A. \& Eaton, D. C. (1979). Journal of Membrane Biology 45, 81-108.

Wirthensohn, K. (1980). Der Stoffwechsel kurzkettiger Fettsaüren im Colonepithel des Meerschweinchens und seine Bedeutung für die Natriumresorption. Dissertation zur Erlangung des grades eines Doktors der Naturwissenschaften an der Fakultät Biologie der Universität Hohenheim.

Yau, W. M. \& Makhlouf, G. M. (1974). Gastroenterology 67, 662-667.

Yorio, T. \& Bentley, P. J. (1977). American Journal of Physiology 1, F5-F9. 